\title{
CICLOESTRATIGRAFIA:ANÁLISE QUANTITATIVA DE CICLOS SEDIMENTARES, APLICAÇÕES NA SEÇÃO SEDIMENTAR DE IDADE OLIGOCENO-MIOCENO DA BACIA DE CAMPOS
}

\author{
NILO CHAGAS DE AZAMBUJA FILHO ${ }^{1}$, MARTIN A. PERLMUTTER ${ }^{2}$
}

\begin{abstract}
CYCLOSTRATIGRAPHY: QUANTITATIVE ANALYSIS OF SEDIMENTARY CYCLES, APPLICATIONS IN THE OLIGOCENE-MIOCENE SUCCESSION OF THE CAMPOS BASIN Quantitative cyclostratigraphic analyses are used to identify the periodic stratigraphic patterns observed in the sedimentary record. This is done by decoding the cyclic changes in the thickness and composition of sedimentary cycles. Statistical techniques have been developed to make easier this task and to determine the periodicity of the cycles. As an example, it is going to be presented a study of the Oligocene-Miocene succession of the Campos Basin, where the carbonate sedimentation, responsible for the amount of calcium carbonate of the slope mudstones, was controlled by the orbital Milankovitch band. A complementary approach using stable oxygen isotopes is also presented, based on bulk samples from cuttings, which allowed a better understanding of the stratigraphic record and its refinement.
\end{abstract}

\begin{abstract}
Resumo As análises cicloestratigráficas quantitativas visam identificar e reconstruir as periodicidades responsáveis pelos padrões estratigráficos observados na natureza e isto é feito através de avaliações das mudanças cíclicas nas espessuras e nas composições dos componentes de um ciclo sedimentar dentro de um arcabouço temporal calibrado. Técnicas estatísticas têm sido desenvolvidas para facilitar essas correlações e determinar a cronologia dos ciclos investigados. Como exemplo desse tipo de análise é apresentado o resultado do estudo realizado na seção do Oligoceno-Mioceno da Bacia de Campos, onde a sedimentação carbonática responsável pelo teor de carbonato nos folhelhos de talude foi controlada pela indução na escala orbital da banda de Milankovitch. Como complemento deste tipo de análise cicloestratigráfica é apresentado um exemplo de como os isótopos estáveis de oxigênio, utilizando rocha total em amostra de calha, podem fornecer informações importantes para o refinamento estratigráfico.
\end{abstract}

INTRODUÇÃO Uma vez estabelecido que, no registro geológico do Pleistoceno, as variaç̃es orbitais têm um papel modulador, é de se esperar que, de algum modo, o mesmo possa ter ocorrido num passado mais distante, de modo que teríamos no registro geológico um marca-passo orbital com valores cronológicos de inestimável valor. Assumindo que este registro orbital esteja preservado em seqüências sedimentares, sua identificação e utilização dependeriam das técnicas para a sua extração.

Neste trabalho será apresentado um exemplo da aplicação da Cicloestratigrafia na seção estratigráfica de idade Oligoceno-Mioceno da Bacia de Campos, onde variações no teor de carbonato de cálcio dos folhelhos possuem sua distribuição ao longo do tempo controlado por indução na escala orbital. Adicionalmente, serão também analisadas as variações dos isótopos estáveis de oxigênio na mesma seção e sua relação com as variações no teor de carbonato.

Parte substancial do que será aqui apresentado é oriundo do trabalho apresentado por Perlmutter \& Azambuja Filho (2005) no capítulo 14 do livro editado por Eduardo Koutsoukos entitulado Applied Stratigraphy, publicado pela Springer, volume 23 - Topics in Geobiology

ANÁLISES QUANTITATIVAS DE CICLOS SEDIMENTARES As variações periódicas da órbita da Terra ao redor do Sol foram quantificadas primeiramente por Milankovitch em 1941. Os ciclos induzidos por essas variações atualmente são denominados de Ciclos de Milankovitch, e eles têm três principais componentes relacionados a aspectos da órbita e inclinação do eixo da Terra, o que afeta a recepção e distribuição do calor oriundo do Sol: excentricidade, obliqüidade e precessão. A órbita da Terra ao redor do Sol é elíptica e possui duas prin- cipais variações da sua órbita as quais possuem periodicidades de aproximadamente $413 \mathrm{Ka}$ e $100 \mathrm{Ka}$. A obliqüidade, ou seja a variação do grau de inclinação do eixo da terra em relação a sua órbita ao redor do Sol tem uma periodicidade de aproximadamente $41 \mathrm{Ka}$. A precessão dos equinócios muda progressivamente a medida em que as estações mudam em função da posição relativa da órbita da Terra ao redor do Sol, possui duas principais periodicidades $19 \mathrm{Ka}$ e $23 \mathrm{Ka}$. Segundo Matthews and Frohlich (1991), devido à interferência desses ciclos, estima-se que possam ser gerados ciclos climáticos de longo período os quais poderiam atingir algo em torno de $2.4 \mathrm{Ma}$. Maiores detalhes serão discutidos mais adiante neste artigo.

O objetivo das análises cicloestratigráficas quantitativas é identificar e reconstruir as periodicidades responsáveis pelos padrões estratigráficos observados na natureza. Comumente, isto é feito através de avaliações das mudanças nas espessuras e nas composições dos componentes de um ciclo dentro de um arcabouço temporal calibrado. Técnicas estatísticas têm sido desenvolvidas para facilitar essas correlações e determinar a cronologia dos ciclos investigados. Schwarzacher (1993) apresenta uma excelente revisão das técnicas matemáticas e estatísticas que têm sido comumente utilizadas para a avaliação dos ciclos sedimentares, incluindo análises espectrais. Ele discute também os requisitos para as análises e os problemas inerentes relativos à tarefa de conversão de espessura em tempo geológico.

Os aspectos mais críticos que afetam a quantificação dos ciclos são a completude do registro sedimentar sob investigação e a densidade de amostragem. Avaliações errôneas podem ocorrer em registros nos quais os componentes do ciclo não foram adequadamente relacionados aos processos que induziram as mudanças nas espessuras, ou à variação litológica ao longo da duração do ciclo, bem como em registros que contenham muitas 
erosões ou hiatos de difícil distinção. Adicionalmente, respostas inconsistentes podem ser originadas como conseqüência de uma densidade de amostragem menor do que o intervalo de variabilidade dos ciclos que se queiram identificar. Bastante cuidado deve ser tomado para que os dados a serem utilizados sejam adequados.

Para que seja possível extrair o tempo e a periodicidade de ciclos sedimentares, é importante entender inicialmente as causas de sua origem. Isto é obtido através da identificação das características sedimentares dos ciclos e dos processos sedimentares que os criaram. Por exemplo, para auxiliar nessa análise Einsele et al. (1991) estabeleceu tipos de acamamentos sedimentares e propôs que os mesmos fossem grupados, tendo como critério a espessura das camadas e a ciclicidade das mesmas (Figuras 1, 2 e 3$)$.

Um outro ponto importante a ser considerado na análise dos ciclos sedimentares está relacionado com a restrição lateral dos dados comumente utilizados para a análise de ciclos, tais como dados de poços, testemunhos e afloramentos. É crucial que seja feita a integração de dados adicionais, tais como seções sísmicas, para complementar o entendimento das variações laterais das propriedades dos ciclos sedimentares.

Uma técnica relativamente nova é a Lacunaridade, que é uma medida multi-escala de uma invariância de translação ou a extensão de um padrão que varia por posição (Plotnick et al. 1993; 1996). Essa técnica tem sido utilizada com sucesso para avaliar os componentes de freqüência de seqüências cíclicas e a contribuição relativa de cada freqüência na variabilidade dos

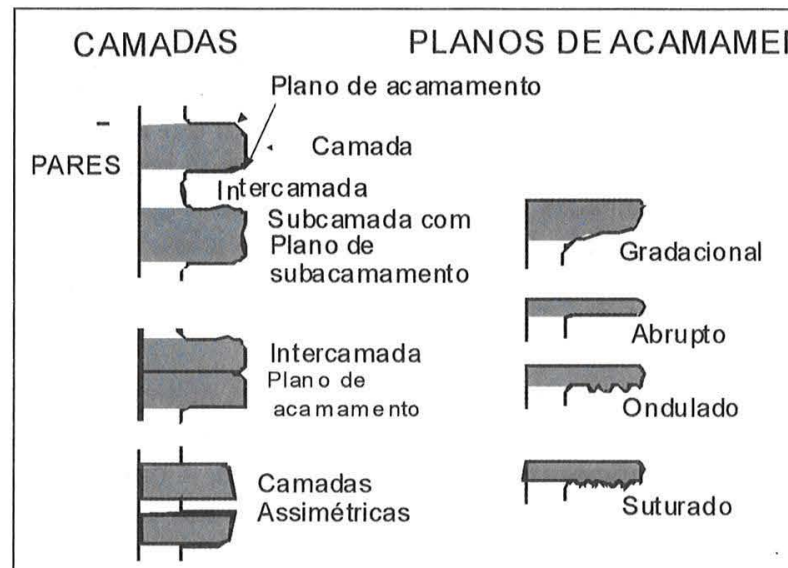

GRUPOS DE CAMADAS E INTERCAMADAS

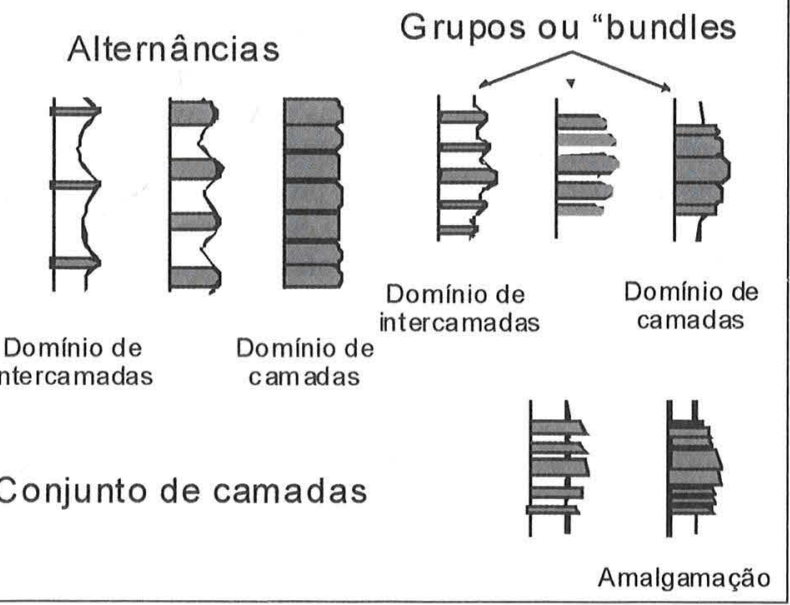

Figura 1 - Termos descritivos para o fenômeno de acamamento segundo Einsele et al. (1991). ciclos (Perlmutter and Plotnick 1997, 2002).

$O$ impacto da resolução dos dados e ferramentas de interpretação A presente discussão está focada em seqüências controladas por forças alocíclicas, ou seja, aquelas geradas por fenômenos externos ao ambiente sedimentar, tais como as variações cíclicas orbitais e as mudanças climáticas, ao contrário das forças autocíclicas que operam dentro de um sistema sedimentar, como, por exemplo, a avulsão de um rio e as tempestades. O intervalo de tempo registrado em um ciclo sedimentar induzido por ciclos orbitais pode variar devido a fatores regionais ou locais tal como as sucessões climáticas. Como conseqüência tornase importante identificar essas variações a fim de fazer as mais acuradas avaliações do intervalo de tempo e das periodicidades dos ciclos. Caso isto seja feito adequadamente a cicloestratigrafia poderá ser utilizada como ferramenta geocronológica.

Contudo, determinar as variações deposicionais dentro de um ciclo não é tarefa fácil. Por exemplo, mudanças nas taxas de acumulação podem causar erros nas interpretações, especialmente quando as taxas de acumulação são interpretadas a partir de perfis de poços. Variações nas espessuras das camadas, combinadas com os limites da resolução vertical dos perfis de poços podem induzir interpretações, que inadvertidamente, combinem ciclos de diferentes periodicidades. Ou seja, a falta de resolução vertical das ferramentas de perfilagem pode induzir o intérprete a erros devido a subamostragem da seção analisada, o que pode gerar ciclos cujas freqüências não possuam ligação com os processos que as causaram (Davis 1986; Figura 4). Para eliminar esse problema o ideal é a utilização de ferramentas que possuam alta resolução vertical. Alternativamente, pode-se utilizar uma técnica que consiste em construir uma matriz na qual possíveis periodicidades são comparadas com possíveis espessuras de camadas ou ciclos, as quais dependem da resolução vertical da ferramenta utilizada, para diversas taxas de acumulação. Esta matriz pode assim ser comparada com a média das taxas de acumulação de uma seção a ser analisada e com isso identificar os intervalos que para cada ferramenta poderia induzir a uma subamostragem, e por conseqüência a erros de interpretação (Tabela 1).

Taxas de sedimentação versus taxas de acumulação A utilização direta de taxas derivadas de sedimentação em ambientes deposicionais modernos para estimar as taxas de sedimentação em seqüências estratigráficas não é um exercício passível de ser realizado diretamente, pois os intervalos de acumulação incluem períodos de erosão ou de não-deposição. Em geral, quanto mais longo for o período de tempo envolvido num intervalo estratigráfico, maior o número de períodos de erosão ou nãodeposição. Como conseqüência, as taxas de deposição a partir de ambientes modernos podem ser significativamente maiores do que as do registro sedimentar antigo (Kukal 1990; Sadler and Strauss 1990).

Um método utilizado para avaliar a completude, ou seja, o quanto uma seção estratigráfica está completa, foi proposto por Schwarzacher (1993). Ele define completude como sendo C (n) $=1-U / n$, onde $C(n)$ é a completude do registro estratigráfico durante um período correspondente de tempo, U é o numero de unidades estratais sem deposição e n é o intervalo de tempo. Visando simplificar as análises, assume-se que as taxas de deposição sejam constantes quando essa equação é aplicada.

Análise espectral Uma vez compreendida a completude da seção estratigráfica a ser estudada, podem ser utilizadas tanto as análises de séries temporais ou de densidade espectral para quantificar a periodicidade de uma seqüência. Em séries temporais, ciclos no registro sedimentar são analisados pelos seus har- 


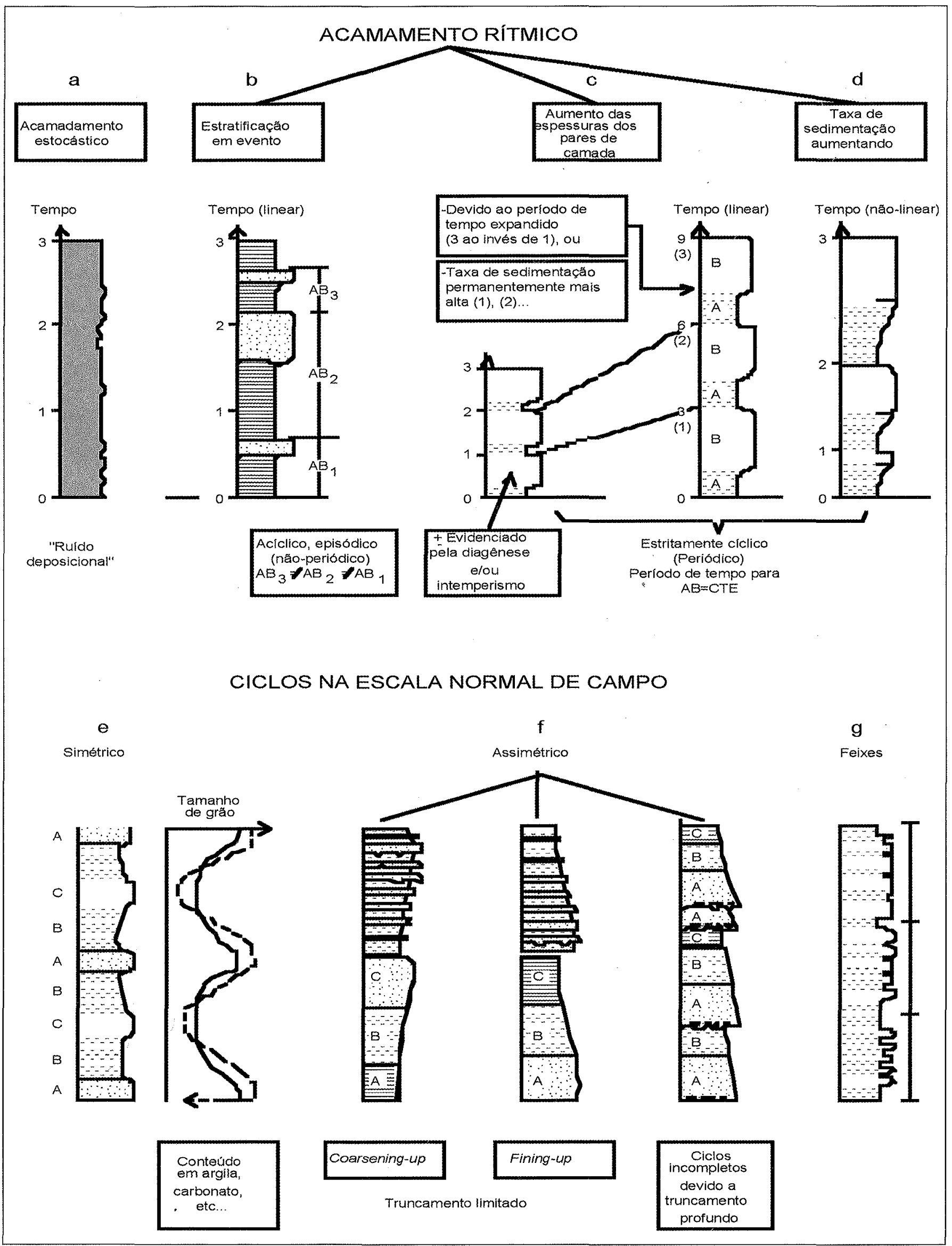

Figura 2 - Nomenclatura utilizada por Einsele et al. (1991) para descrever ritmos e sequiências sedimentares cíclicas de diferentes origens, espessuras e de periodos de tempo em afloramentos. As grandezas das ordens dos ciclos estão entre parêntesis e referem-se aos termos segundo Vail et al. (1977") e Haq et al. (1987). O termo megaciclo é aqui usado para representar um conjunto de superciclos segundo in Haq et al. (1987). 


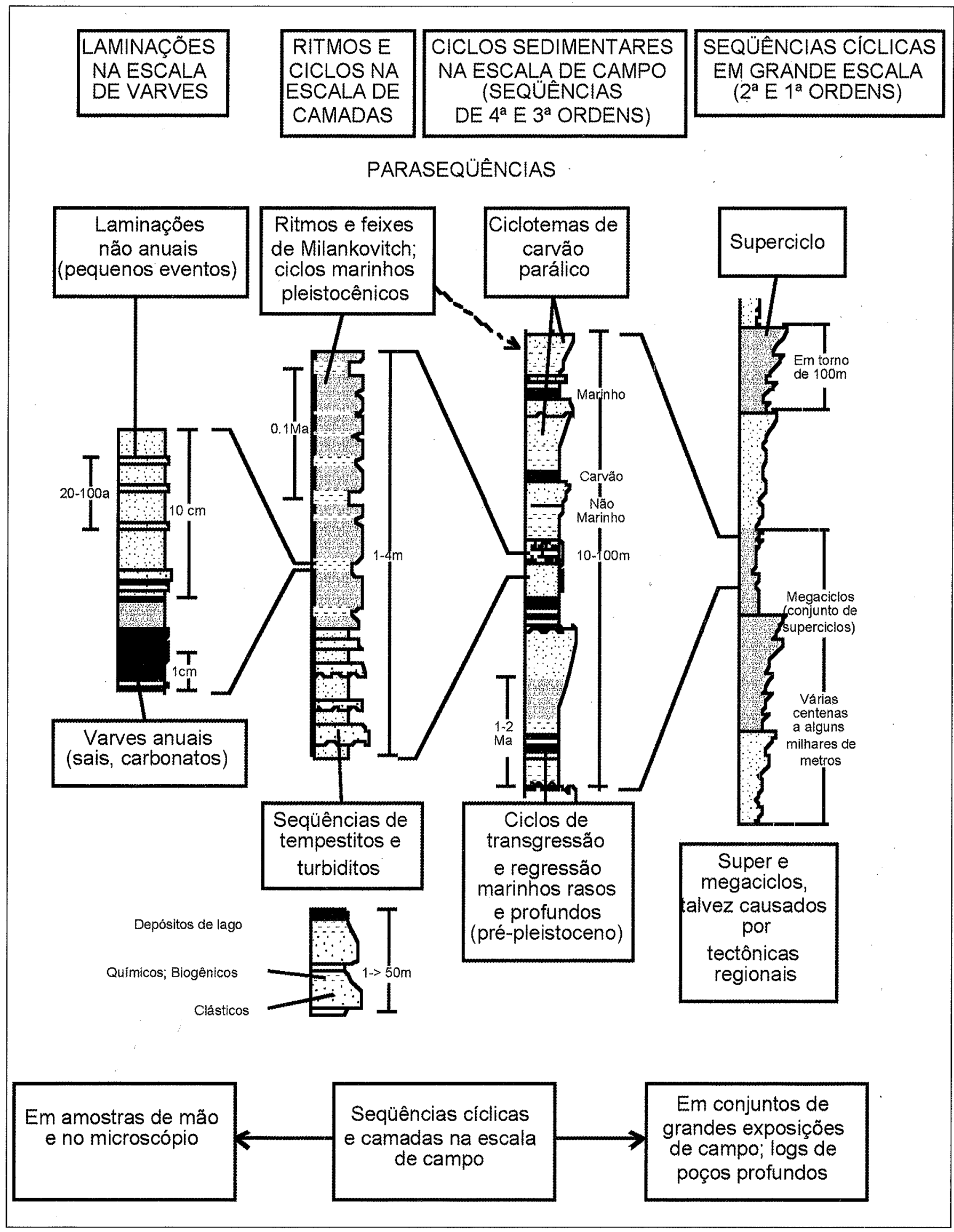

Figura 3 - Acamamento estocástico (a), e diferentes tipos de ritmos sedimentares $(b-d)$ e sucessões sedimentares cíclicas $(e-g)$. Todas as seqüências podem ser estritamente cíclicas ou periódicas (c e d) ou não periódicas (b). A espessura dos tipos correspondentes de acamamento pode mudar de ciclo devido a variações tanto no periodo de tempo (c) dos ciclos subseqüentes quanto nas taxas de acumulação (c e d). Acamamentos rítmicos causados por eventos deposicionais (b) podem mostrar alterações simi-lares às seqüências cíclicas, mas elas são normalmente não cíclicas ou não periódicas. (modificado de Einsele et al., 1991). 
mônicos ou componentes de ciclos (Chatfield 1989). O método mais comum de análise quantitativa utiliza a transformada rápida de Fourier (FFT - fast Fourier transform), que faz a decomposição da função total da curva (gráfico) em funções senoidais. Através da FFT podemos transformar um gráfico construído a partir de informações estratigráficas de espessura versus quaisquer características físicas, químicas, visuais ou composicionais da rocha, para um gráfico de amplitude versus período ou freqüência. Esse processo facilita enormemente a visualização dos ciclos no trecho que se quer analisar, já que aparecerão picos de amplitude tanto maiores quanto forem as repetições de espessuras similares. Para a utilização da análise espectral é necessária

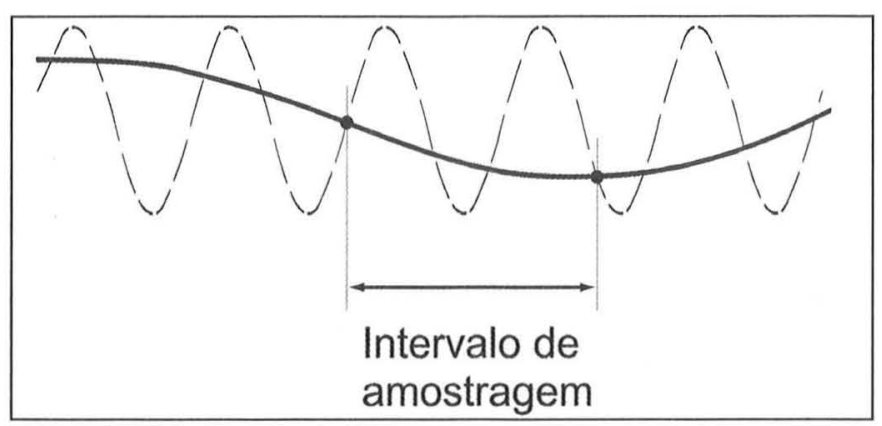

Figura 4 - Curva senoidal de alta freqüência (linha tracejada) amostrada a intervalos discretos criando uma nova curva com uma freqüência aparente mais baixa (linha cheia). A freqüência da linha original é mais alta do que a freqüência de Nyquist para o intervalo amostrado, ou seja, necessita-se de mais pontos de amostragem para identificar corretamente a freqüencia correta (modificado de Davis, 1986). uma modificação na análise de Fourier, visando adequá-la a valores estocásticos, o que pode ser atingido, apenas parcialmente através dos valores anteriores, mais do que uma função determinística do tempo na qual uma serie temporal pode ser predita (Schwarzacher 1975). A análise espectral consiste na detecção de freqüências dominantes em séries temporais. Como artifício, entretanto, é perfeitamente válido considerarmos os perfis geofísicos de poço como uma série, só que em vez de tempo na escala vertical, teremos espessuras. Logo, nosso espectro analisado será de períodos, os quais se divididos por uma taxa de deposição, resultariam em freqüências temporais. Programas de análise estatística normalmente possuem como uma das opções a transformada rápida de Fourier, como exemplo pode-se citar o programa STATISTICA for Windows, Release 4.3 da StatSoft, de 1993, utilizado nas análises apresentadas neste trabalho.

Um método alternativo para a identificação dos ciclos é o escalograma que utiliza a equação da onda. Maiores detalhes desta técnica serão apresentados nesta publicação por Cunha e Azambuja Filho sob o titulo Análise da periodicidade dos folhelhos negros do poço DSDP-530 (bacia de Angola): um estudo comparativo entre a análise espectral utilizando harmônicos e wavelet.

Um modo comparativo para entendermos como uma análise espectral reconhece as freqüências contidas ou "escondidas" numa série temporal é utilizarmos um experimento no qual um feixe de luz branca atravessa um prisma, sendo o mesmo decomposto em um espectro de cores com suas freqüências (Davis 1986; Figura 5).

\section{APLICAÇÃO DA ANÁLISE ESPECTRAL EM SEQÜÊNCIAS SEDIMENTARES}

Método Existe uma série de trabalhos relacionando ciclos sedimentares às oscilações climáticas e aos ciclos orbitais, bem

Tabela 1 Matriz comparando taxas de acumulação para as principais periodicidades e suas correspondentes espessuras de ciclos.

\begin{tabular}{|c|c|c|c|c|c|c|c|c|c|c|c|}
\hline \multirow{4}{*}{ 号 } & \multicolumn{11}{|c|}{ PERIODICIDADES } \\
\hline & \multicolumn{5}{|c|}{ Banda de Milankovitch ka } & \multicolumn{5}{|c|}{ Ciclos solares } & \multirow[t]{2}{*}{ El Niño } \\
\hline & 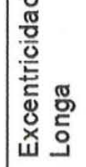 & 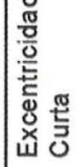 & $\begin{array}{l}\frac{0}{0} \\
\frac{\pi}{0} \\
\frac{\pi}{0} \\
\frac{0}{0} \\
0 \\
0\end{array}$ & 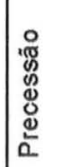 & 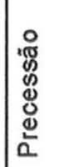 & 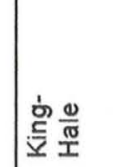 & 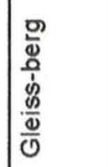 & \begin{tabular}{|l}
$\frac{0}{0}$ \\
$\frac{\sigma}{1}$ \\
$\frac{0}{0}$ \\
$\frac{0}{3}$ \\
0
\end{tabular} & $\frac{0}{\frac{0}{\pi}}$ & $\begin{array}{l}\frac{D}{\sigma} \\
\frac{\pi}{\omega} \\
\frac{\sum}{\omega}\end{array}$ & \\
\hline & 410 & 100 & 41 & 23 & 19 & $180 a$ & $80 a$ & $44 a$ & $22 \mathrm{a}$ & $11 \mathrm{a}$ & $5 a$ \\
\hline $\begin{array}{l}\text { Taxas } \\
\mathrm{cm} / \mathrm{ka}\end{array}$ & \multicolumn{11}{|c|}{ Espessura dos ciclos em metros } \\
\hline 1 & 4,1 & 1 & 0,4 & 0,2 & 0,2 & 0,0018 & 0,0008 & 0,00044 & 0,00022 & 0,00011 & 0,00005 \\
\hline 2 & 8,2 & 2 & 0,8 & 0,5 & 0,4 & 0,0036 & 0,0016 & 0,00088 & 0,00044 & 0,00022 & 0,0001 \\
\hline 5 & 20,5 & 5 & 2,1 & 1,2 & 1 & 0,009 & 0,004 & 0,0022 & 0,0011 & 0,00055 & 0,00025 \\
\hline 10 & 41 & 10 & 4,1 & 2,3 & 1,9 & 0,018 & 0,008 & 0,0044 & 0,0022 & 0,0011 & 0,0005 \\
\hline 15 & 61,5 & 15 & 6,2 & 3,5 & 2,9 & 0,027 & 0,012 & 0,0066 & 0,0033 & 0,00165 & 0,00075 \\
\hline 20 & 82 & 20 & 8,2 & 4,6 & 3,8 & 0,036 & 0,016 & 0,0088 & 0,0044 & 0,0022 & 0,001 \\
\hline 30 & 123 & 30 & 12 & 6,9 & 5,7 & 0,054 & 0,024 & 0,0132 & 0,0066 & 0,0033 & 0,0015 \\
\hline 50 & 205 & 50 & 21 & 12 & 9,5 & 0,09 & 0,04 & 0,022 & 0,011 & 0,0055 & 0,0025 \\
\hline 100 & 410 & 100 & 41 & 23 & 19 & 0,18 & 0,08 & 0,044 & 0,022 & 0,011 & 0,005 \\
\hline 1000 & 4100 & 1000 & 410 & 230 & 190 & 1,8 & 0,8 & 0,44 & 0,22 & 0,11 & 0,05 \\
\hline 2000 & 8200 & 2000 & 820 & 460 & 380 & 3,6 & 1,6 & 0,88 & 0,44 & 0,22 & 0,1 \\
\hline
\end{tabular}




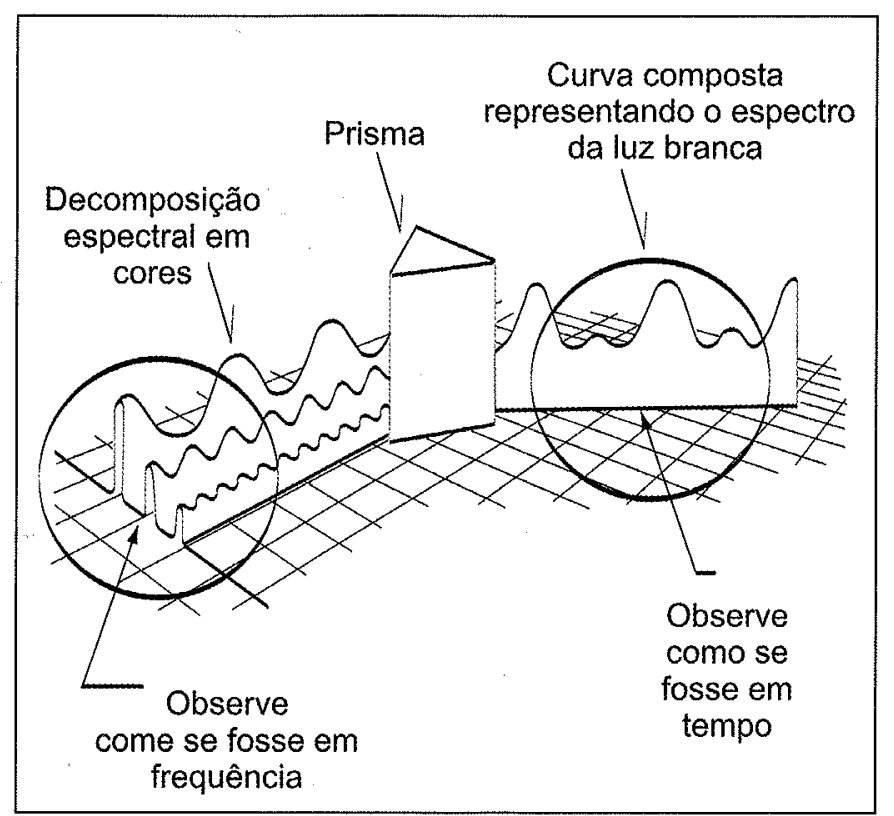

Figure 5 - Uma onda composta por varias freqüências pode ser deconvolvida em suas componentes. Esse é um principio similar ao modo pelo qual um prisma decompõe a luz branca em um espectro de cores (modificado de Davis 1986).

como as mudanças de mais alta freqüência tal como os ciclos solares e de marés. Análises em sedimentos, depositados durante o Pleistoceno, tem de fato demonstrado que as oscilações climáticas, que podem variar de milhares até milhões de anos, estão associadas às variações da órbita da Terra (Imbrie \& Imbrie 1979).

Como já mencionado acima, é necessário cautela quando da conversão da espessura para tempo geológico, especialmente porque a maioria dos processos sedimentares não produz acumulações contínuas nem constantes, causando deste modo uma distorção na conversão da espessura do ciclo em tempo. Adicionalmente, mudanças nas condições de intemperismo e deposicional em um ciclo climático podem causar variações na litologia. Essas mudanças litológicas podem ser bastante significantes, a depender da localização do ponto analisado e pode fazer com que o número de camadas num ciclo seja erroneamente interpretado (Perlmutter and Matthews 1989). Para dificultar ainda mais existe a sobreposiçao de processos diagenéticos, que imprimem "ruídos" adicionais sobre os ciclos sedimentares. Assim sendo, deve-se optar pela seleção de seções sedimentares com acamamento rítmico visível, pois quando as seções não mostram claramente esta propriedade existe uma alta probabilidade de o interprete ser induzido a fazer deduções errôneas.

Um métodó para converter a espessura em tempo é reconstruir as periodicidades astronômicas responsáveis pela indução dos ciclos através dos padrões estratigráficos, o que pode ser feito da seguinte forma: (1) selecione um intervalo estratigráfico de um poço cujos perfis geofísicos apresentem ciclos sedimentares com espessuras relativamente uniformes (Figura 6), caso existam muitas variações nas espessuras dos ciclos divida-o em intervalos menores; (2) faça uma estimativa do intervalo de tempo compreendido no intervalo analisado utilizando dados bioestratigráficos; (3) determine a taxa de acumulação média para o intervalo dividindo a espessura pelo tempo obtido da bioestratigrafia; (4) determine a resolução vertical da ferramenta utilizada (ou seja, o intervalo de amostragem, lembrando que para que um ciclo seja amostrado necessita-se de pelo menos três amostras por comprimento de onda como visto na Figura 4), e compare a espessura dos ciclos esperados teoricamente para esse intervalo tomando como base a média da taxa de acumulação obtida no item 3 e compare com a matriz da Tabela 1; (5) a amostragem das propriedades deve ser a intervalos constantes, como normalmente ocorre com a amostragem nos perfis geofísicos de poços, o que não é normalmente o caso quando são utilizados dados de laboratórios ou de outras fontes, neste caso é necessário fazer uma reamostragem; (6) determine a presença das freqüências contidas no intervalo através da análise espectral utilizando o periodograma do intervalo; (7) calcule a espessura dos ciclos sedimentares através da divisão do intervalo de amostragem pelas frequiências mais significantes obtidas no periodograma com o auxílio da análise espectral (Figura 7.); (8) com base nas espessuras obtidas no item anterior, construa uma matriz com as razões das espessuras obtidas dos ciclos e faça a comparação com a matriz com as razões resultantes das periodicidades da banda dos ciclos orbitais de Milankovitch (Tabelas 2 e 3 ). Selecione apenas os valores das razões das matrizes que possuam mais $90 \%$ de similaridade entre si ou $95 \%$ caso queira uma maior restrição; (9) faça uma comparação das razões selecionadas das correspondentes espessuras e períodos de Milankovitch relacionando com as correspondentes taxas medias de sedimentação obtidas no item 3 ; (10) selecione aqueles ciclos que possuam a melhor correlação de similaridade com as taxas de sedimentação (Tabela 5); (11) conte o número de ciclos no intervalo e multiplique pela periodicidade obtida para estabelecer o intervalo de tempo da seção preservada. Caso exista um hiato significativo de tempo na seção, que não tenha sido detectado, ocorrerá uma discrepância entre as taxas de acumulação obtidas através da comparação com a matriz da banda de períodos de Milankovitch com as taxas médias obtidas com base na bioestratigrafia. Um outro tipo de discrepância que pode ocorrer e está exemplificado neste estudo de caso na espessura dos ciclos relativo à excentricidade longa. No exemplo, obteve-se com a análise espectral um ciclo de $18,66 \mathrm{~m}$, o que equivale a uma taxa de acumulação de $4,82 \mathrm{~cm} / \mathrm{ka}$, enquanto a análise visual do perfil os ciclos possuem espessuras na ordem de $21 \mathrm{~m}$ (Figura 6) o que corresponderia a uma taxa de $5,08 \mathrm{~cm} / \mathrm{ka}$. Como conseqüência, se utilizarmos as taxas de acumulação correspondentes ao ciclo de 18,66 m as mesmas ficariam menores, quando comparadas com a das outras periodicidades (vide a Tabela 4). Essa diferença na espessura dos ciclos obtidos pela análise espectral e a dos ciclos obtidos diretamente do perfil é devido ao tamanho do intervalo analisado ser menor do que o necessário para que o comprimento de onda de baixa freqüência ficasse devidamente amostrado. Para solucionar esse problema basta aumentar o intervalo analisado e refazer a análise espectral. Como orientação sugere-se sempre uma fase de análise das magnitudes dos ciclos a serem analisados antes de se utilizar métodos estatísticos, isto facilitará bastante a interpretação dos resultados.

Procedimento similar pode ser utilizado com um traço sísmico, como foi realizado por Castro (1999). A diferença básica está na resolução vertical, onde o registro sísmico possui uma baixa resolução quando comparado com o dado de perfil em um poço. Como consequiência, somente os ciclos mais longos serão passíveis de identificação.

Aplicação da cicloestratigrafia na seção sedimentar de idade Oligoceno - Mioceno da Bacia de Campos A seção sedimentar de idade Oligoceno-Mioceno da Bacia de Campos é composta principalmente por uma alternância de folhelhos e margas e subordinadamente por níveis com carbonatos ricos em nanofósseis (chalk) e arenitos turbidíticos, latu sensu. Parte desta seção, correspondente ao intervalo de tempo de idade Mioceno Inferior já foi ilustrada na seção sobre metodologia acima 
através das figuras 6 e 7 e pelas tabelas 2 a 4 .

Uma seção rítmica de idade Oligoceno composta por intercalações de margas e folhelhos foi amostrada continuamente por dois testemunhos, totalizando $27 \mathrm{~m}$ recuperados (Figura 8). O testemunho foi amostrado com um espaçamento constante de $5 \mathrm{~cm}$ para análise da percentagem de $\mathrm{CaCO}_{3}$ e seus resultados plotados contra profundidade na Figura 9. Observando o gráfico da Figura 9 percebe-se visualmente uma variação sistemática na percentagem relativa de $\mathrm{CaCO}_{3}$ comparado com a quantidade de resíduo insolúvel, ou seja, silte mais argila. É possível distinguir pelo menos duas freqüências de variações, contudo fica difícil sua quantificação efetiva. Para auxiliar na quantificação das freqüências e correspondentes comprimentos de onda, ou seja, a espessura dos ciclos carbonáticos, procedeu-se à análise espectral dos dados, tendo sido obtidos os seguintes resultados: foram encontrados quatro grupos de ciclos com espessuras variando de 20 a $25 \mathrm{~cm}, 42$ a $50 \mathrm{~cm}, 120 \mathrm{~cm}$ e $420 \mathrm{~cm}$ (Figura 9).

Seguindo os procedimentos discutidos na parte metodológica nas seções acima, procedeu-se o cálculo da taxa média de acumulação para a seção do Oligoceno na área do poço, tendo sido obtido um valor que varia de 1 a $1,2 \mathrm{~cm} / \mathrm{Ka}$. Azambuja Fitho (1990) e Azambuja Filho \& Azevedo (1995) fazendo a comparação das razões das espessuras dos ciclos encontrados com as razões dos períodos orbitais de Milankovitch obtiveram uma boa correspondência, possibilitando associar as periodicidades orbitais de precessão e excentricidade curta e longa com os ciclos carbonáticos de 20 a $25 \mathrm{~cm}$ e $120 \mathrm{~cm}$ e $420 \mathrm{~cm}$, respectivamente, indicando um forte controle na sedimentação carbonática-siliciclástica. Os ciclos relativos às espessuras de 42 a $50 \mathrm{~cm}$ neste intervalo mostram-se menos desenvolvidos e são aqui interpretados como correspondentes às induções pela obliqüidade. Contudo, em intervalos do Mioceno Médio a Superior os ciclos associados à obliquiidade passam a ser os dominantes. Imbrie et al. (1984) analisando isótopos de foraminíferos constatou que no período de $1500 \mathrm{Ka}$ a $1000 \mathrm{Ka}$, antes do presente, os ciclos dominantes eram de obliqüidade, e que os ciclos no intervalo de $1000 \mathrm{Ka}$ a $500 \mathrm{Ka}$ demonstravam uma zona de transição, passando para os últimos $500 \mathrm{Ka}$ a serem dominados pelos ciclos de precessão e excentricidade curta $(100 \mathrm{Ka})$, indicando que essas relações se alteram para determinados períodos de tempo geológico. O possível controle desta alternância no domínio dos ciclos seria a excentricidade, quando esta se aproximasse de zero, a insolação deixaria de ser dominada pela precessão e passaria para o domínio da obliqüidade (para maiores detalhes, vide página 18 nessta publicação).

Análises similares também realizadas por Castro (1999), para o mesmo intervalo estratigráfico, em um traço sísmico de uma seção sísmica com uma feição progradacional do talude do Mioceno (biozona de nanofósseis da Petrobras N-560) mostram que, quando comparadas com as freqüências encontradas no perfil sônico, ocorre uma redução no conteúdo das altas freqüências do traço de amplitude sísmica na parte inferior do poço, a profundidades superiores a $2200 \mathrm{~m}$. Interpreta-se esse fato a um aumento da velocidade intervalar como conseqüência do incremento no teor de $\mathrm{CaCO}_{3}$. O que por sua vez representa um substancial decréscimo na taxa de acumulação e um relativo aumento na concentração de carapaças de foraminíferos e nanofósseis, caracterizando uma zona condensada, com taxas na ordem de $1 \mathrm{~cm} / \mathrm{ka}$, quando comparada com as seções mais superiores que possuem taxas maiores do que $5 \mathrm{~cm} / \mathrm{ka}$. Para ilustração observe as figuras 6,11, 12 e 13 e Tabela 4 (modificado de Castro 1999).

Esse incremento na taxa de acumulação devido a progradação do talude do Mioceno é visível na sísmica, em perfis e em dados de testemunho. A combinação das altas taxas de acumulação com as relativas baixas velocidades intervalares nessa seção

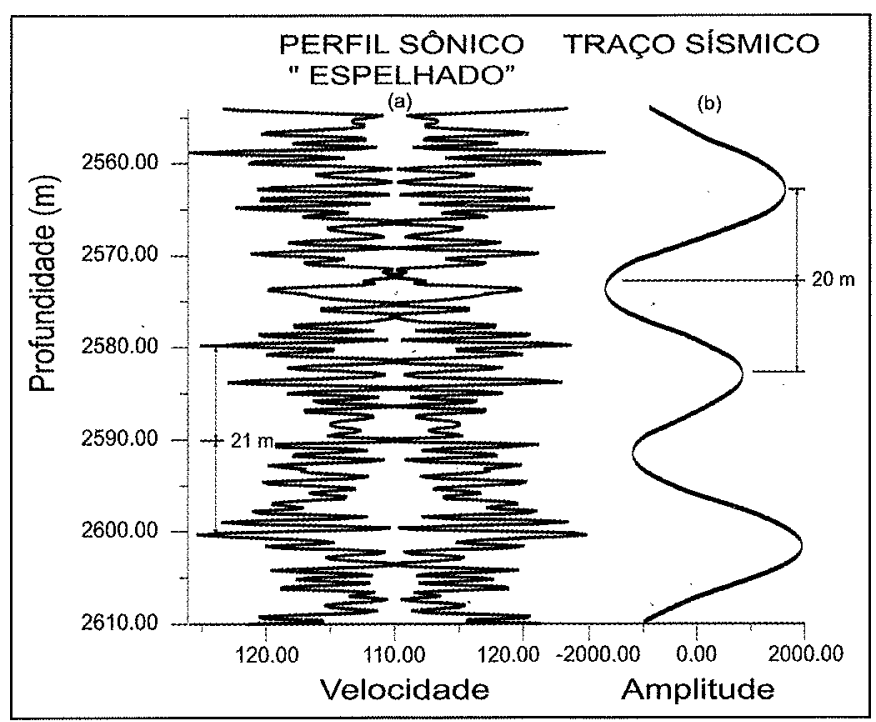

Figura 6 - Intervalo selecionado de um poço mostrando o perfil sônico na sua disposição convencional e o mesmo espelhado ou invertido, com vistas a ressaltar os ciclos (a) e um traço sísmico de amplitude, correlacionado com o sônico em profundidade (b). Note a boa definição do padrão cíclico nos dois tipos de registros. As variações das propriedades geofisicas estão refletindo a variação relativa entre a quantidade de folhelho comparado com a quantidade de carbonato (modificado de Castro 1999).

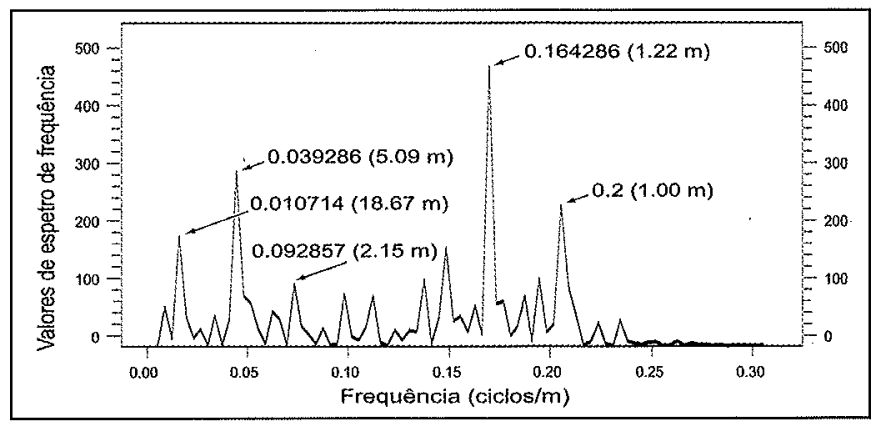

Figura 7 - Periodograma mostrando as freqüências principais, resultantes da análise espectral da curva do perfil sônico do intervalo mostrado na Figura 6, e a espessura correspondente do ciclo de um intervalo estratigráfico pertencente a biozona de nanofósseis da Petrobras - N560a (Mioceno Inferior).

Tabela 2 Matriz mostrando as razões das espessuras dos ciclos em metros. Adjacentes aos valores das razões. Entre parênteses, estão anotadas as razões correspondentes da matriz de periodicidade de Milankovitch, cujos valores apresentaram similaridades iguais ou superiores a 95\%.

\begin{tabular}{|c|ccccc|}
\hline \multicolumn{7}{|c|}{ MIL ANKOVITCH MATARIX } \\
\hline Ka & 410 & 100 & 41 & 23 & 19 \\
\hline 410 & 1,00 & 4,10 & 10,00 & 17,83 & 21,58 \\
100 & & 1,00 & 2,44 & 4,35 & 5,26 \\
41 & & & 1,00 & 1,78 & 1,78 \\
23 & & & & 1,00 & 1,21 \\
19 & & & & & 1,00 \\
\hline
\end{tabular}


Tabela 3 Matriz mostrando as razóes das periodicidades de Milankovitch.

\begin{tabular}{|c|c|c|c|c|c|c|c|c|c|}
\hline m & 18,66 & $\$, 09$ & & 2,15 & & 1,21 & & 1 & \\
\hline 18,66 & 1,00 & 3,66 & $(4,10)$ & 8,68 & $(10,00)$ & 15,42 & $(17,83)$ & 18,66 & $(21,58)$ \\
\hline$s, 99$ & & 1,00 & & 2,36 & $(2,44)$ & 4,20 & $(4,35)$ & 5,09 & $(5,20)$ \\
\hline 2,15 & & & & 1,00 & & 1,77 & $(1,78)$ & 2,15 & $(2,16)$ \\
\hline $\mathbf{1 , 3 1}$ & & & & & & 1,000 & & 1,21 & $(1,21)$ \\
\hline 1 & & & & & & & & 1,00 & \\
\hline
\end{tabular}

Tabela 4 Correlação das espessuras dos ciclos com as periodicidades de Milankovitch e correspondentes taxas de acumulação.

\begin{tabular}{|c|c|c|}
\hline $\begin{array}{l}\text { Sedl mentary cycle } \\
\text { (thkkkness } \\
\text { (mi) }\end{array}$ & $\begin{array}{l}\text { Corresponding } \\
\text { MIlankowiteh } \\
\text { pertod } \\
\text { (ka) }\end{array}$ & $\underset{(\mathrm{cm} / \mathbf{k} \mathbf{a})}{\text { Aceunum ration }}$ \\
\hline 18,66 & 410 & 4,55 \\
\hline 5,09 & 100 & 5,09 \\
\hline 2,15 & 41 & $\mathbf{5 , 2 5}$ \\
\hline 1,21 & 23 & 5,29 \\
\hline 1,00 & 19 & 5,26 \\
\hline
\end{tabular}

do Mioceno permite uma boa resolução sísmica vertical o que permite identificar e quantificar as oscilações no teor de $\mathrm{CaCO}_{3}$ e estabelecer a sua relação com os ciclos orbitais de excentricidade curta (100 ka) e longa ( $413 \mathrm{ka}$ ) identificados também no perfil sônico (Tabela 4 e figuras 6 e 12). Contudo, devido a sua mais alta resolução vertical, o perfil sônico permite a identificação das periodicidades de mais alta freqüência e que estão associadas com a obliquiidade e com a precessão. Como conseqüência desta comparação, é possível ter confiança na aplicação das técnicas da cicloestratigrafia em dados sísmicos que possuam altas freqüências. Cabe salientar que se espera melhores resultados em intervalos estratigráficos com alta taxa de acumulação e preferencialmente, baixa velocidade intervalar.

Uma aplicação da cicloestratigrafia como refinamento estratigráfico e geocronológico foi realizada na mesma seção do Oligoceno-Mioceno da Bacia de Campos. Analisando o perfil de um poço em águas profundas observa-se a presença de dois tipos de padrões estratigráficos (Figura 14a e 14b). Um caracterizado por depósitos espessos (dezenas de metros) de arenitos, cujo padrão em perfis pode ser classificado como em formato de "caixote" com base e topos abruptos com os depósitos hemipelágicos de marga e folhelhos e intervalos mais freqüentes e mais delgados (alguns metros) imersos. A análise cicloestratigráfica determinou que os arenitos delgados recorreriam a intervalos de aproximadamente 400 a $500 \mathrm{ka}$, o que equivaleria a ciclos de excentricidade longa. Já os eventos com arenitos de maior espessura, apresentam uma recorrência que varia de 1,2 a 1,5 Ma, provavelmente resultante da superposição de efeitos de alta periodicidade (Azambuja Filho, 1990). Uma representação esquemática deste tipo de repetição está exemplificada na Figura 15 , onde são distribuídos os principais eventos turbidíticos ocorrentes durante o Oligoceno e Mioceno na região de águas profundas da Bacia de Campos.

Aplicação da cicloestratigrafia em dados isotópicos na seção do Oligoceno-Mioceno da Bacia de Campos Como visto acima, a seção sedimentar de idade Oligoceno-Mioceno

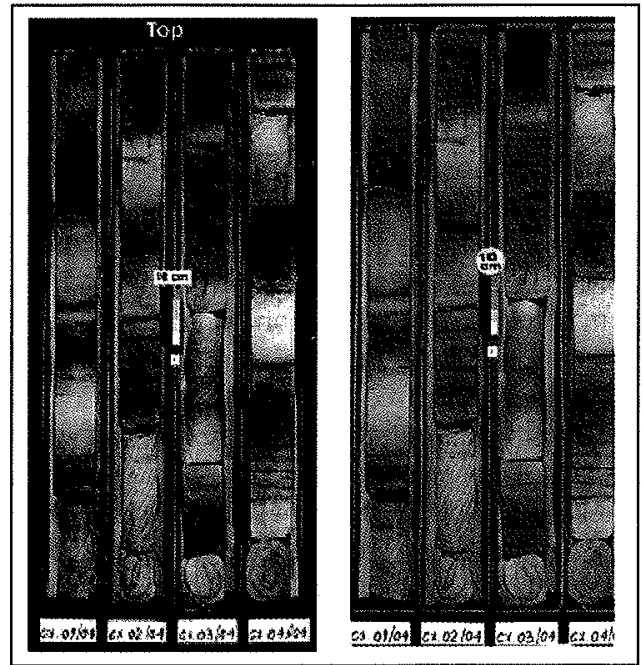

Figura 8 Acamamento ritmico de margas e folhelhos depo. sitados em ambiente batial durante o Oligoceno na Bacia de Campos (modificado de Azambuja Filho 1990). Observe que, visualmente, é possivel identificar a presença de ciclos clarosescuros com espessuras em torno de 20 a $25 \mathrm{~cm}$ representando a variação no conteúdo de $\mathrm{CaCO}_{3}$. A taxa de acumulação regional para este intervalo estratigráfico é de 1 a $1,2 \mathrm{~cm} / \mathrm{ka}$. A escala na foto tem $10 \mathrm{~cm}$ de comprimento.

é representada por folhelhos, margas e turbiditos, depositados em ambiente batial, e apresenta uma ritmicidade dos ciclos de percentagem de $\mathrm{CaCO}_{3}$, cuja periodicidade foi interpretada por Azambuja Filho (1990) como tendo sido controlada pelas variações de insolação associada aos ciclos orbitais da banda climática de Milankovitch.

Azevedo et al. (1994) e Azambuja Filho e Azevedo (1995) realizaram um estudo detalhado de isótopos estáveis de oxigênio realizados na seção do Oligoceno ao Mioceno Inferior da Bacia de Campos, utilizando a mesma metodologia, onde foram selecionadas amostradas de testemunho, espaçadas de $5 \mathrm{~cm}$, e feitas análises tanto do teor de $\mathrm{CaCO}_{3}$ quanto dos valores de isótopos estáveis de oxigênio e carbono em amostras de rocha total. Este estudo complementar, com mais alta resolução vertical, confirma o forte controle da sedimentação carbonática pela excentricidade e pela precessão. Já as variações isotópicas nos valores de $\delta^{18} \mathrm{O}$, apesar de serem perceptíveis nas análises, não mostram um controle tão evidente na escala orbital como o dos carbonatos (Figura $16 \mathrm{a} \mathrm{e} \mathrm{b}$ ).

Por outro lado observa-se que numa escala de duração mais longa, a assinatura isotópica da variação nos valores de $\delta^{18} \mathrm{O}$ destas rochas registrou os principais eventos isotópicos reconhecidos por Miller et al. (1991) em poços do projeto DSDP (Deep Sea Drilling Project). No projeto do DSDP as análises isotópicas foram executadas em foraminíferos bentônicos, enquanto que neste estudo as análises foram executadas em rocha total de dois poços (poços A e B), distantes cerca de $40 \mathrm{~km}$. Azevedo et al. (1994) e Azambuja Filho e Azevedo (1995) demonstraram que é viável a utilização de amostras de calha em análises isotópicas de rocha total na subdivisão de espessas seções sedimentares, não muito afetadas por diagênese. Isto foi concluído com base na coerência obtida a partir da análise de 1000 amostras, e pela comparação dos resultados obtidos de rocha total com os obtidos de amostras que utilizaram carapaças de foraminíferos bentônicos, bem como de comparações de amostras de calha e testemunhos e dados isotópicos do Quaternário.

Os resultados indicam que a seção sedimentar do Oligoceno 


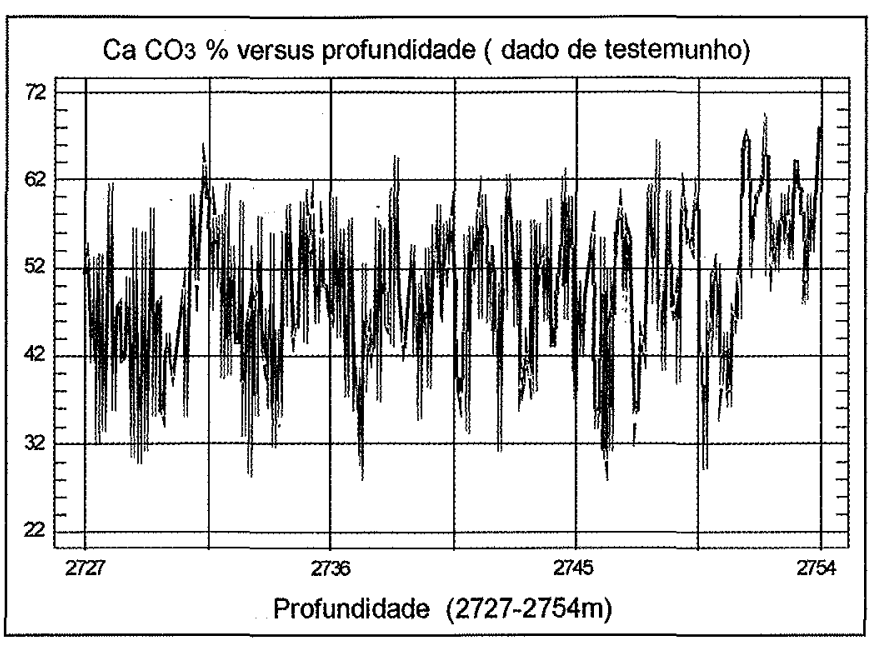

Figura 9 - Gráfico mostrando a variação do conteúdo carbonático, em percentagem, no intervalo testemunhado mostrado na Figura 8. Observe que as variações no conteúdo carbonático possuem duas freqüências principais, uma com espessuras na escala de $25 \mathrm{~cm}$, definida pela variação nas fotos de claro-escuro e outra menos visivel na escala métrica. A variação do conteúdo carbonático reflete basicamente uma maior concentração em nanofósseis e foraminiferos comparados ao conteúdo dos mesmos nos folhelhos (modificado de Azambuja Filho 1990).

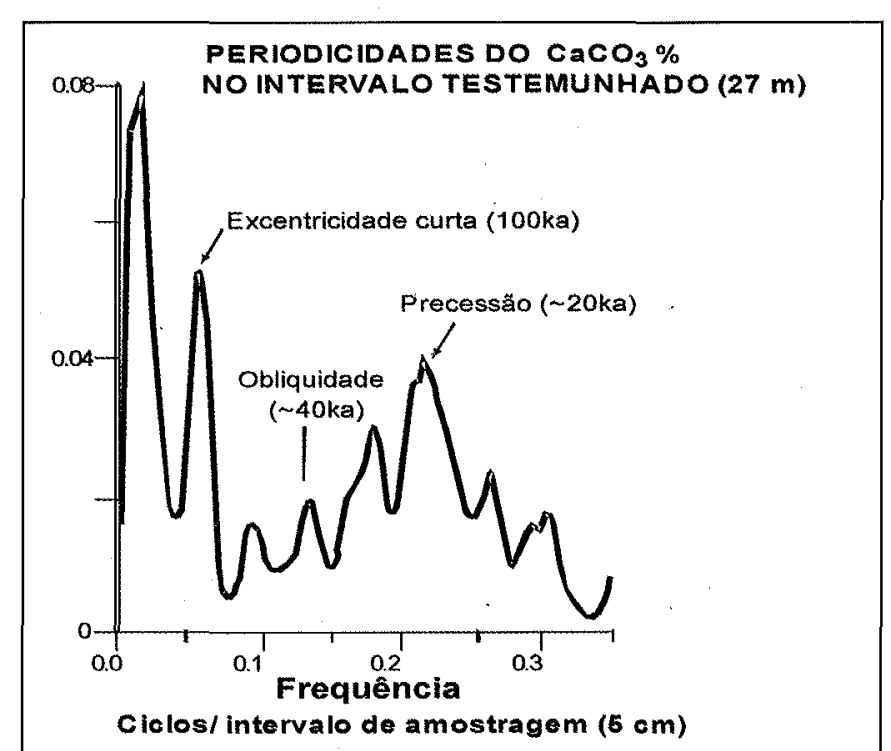

Figura 10 Periodograma mostrando as freqüências dominantes e correspondentes periodicidades da banda de Milankovitch para o intervalo testemunhado. A conversão das freqüências em espessuras, ou seja o comprimento de onda, é obtido dividindo o intervalo de amostragem $(5 \mathrm{~cm})$ pela freqüiencia obtida no periodograma.

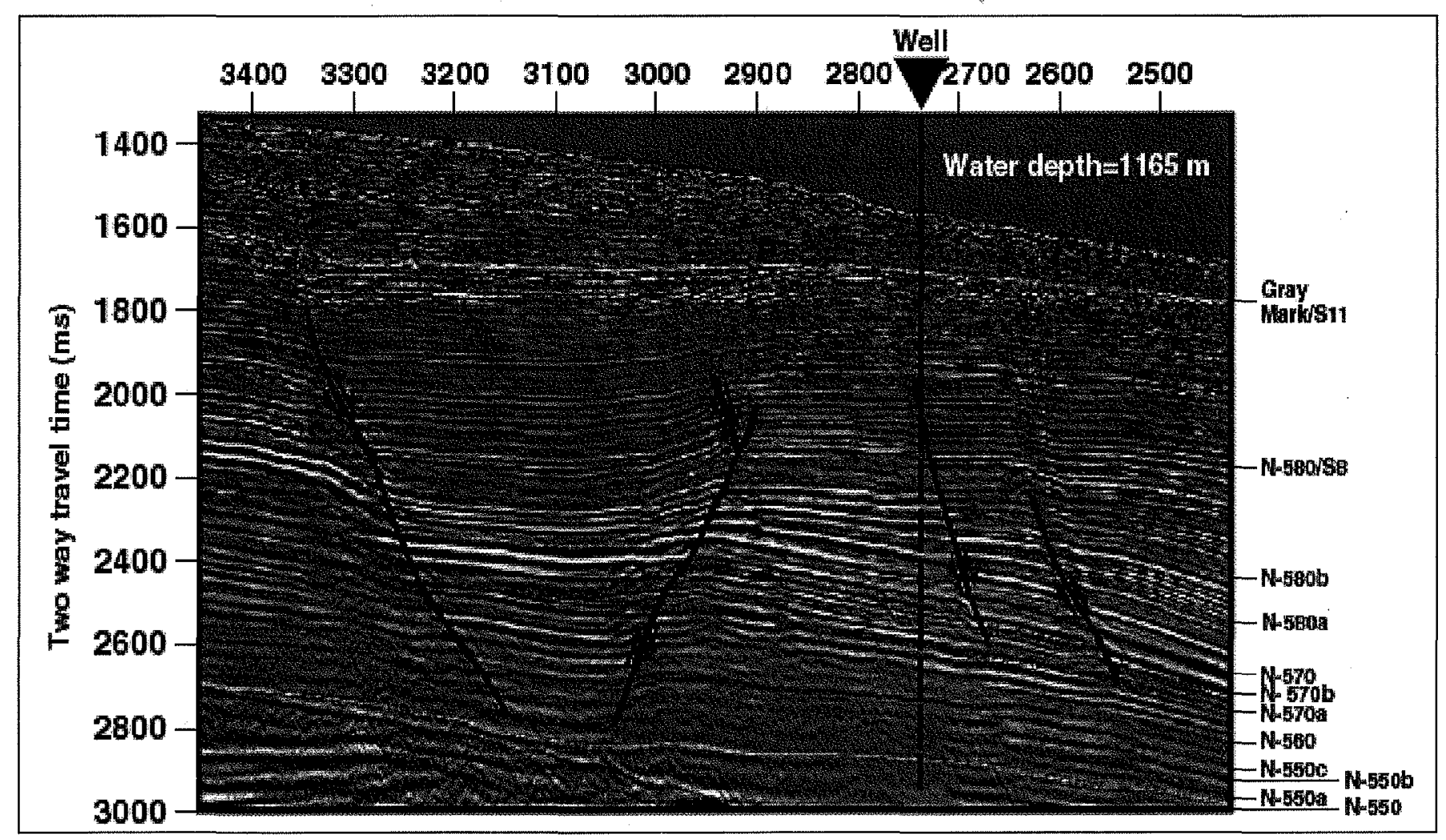

Figura 11 Seção sísmica mostrando a localização de um poço e a feição progradacional do talude do Mioceno (biozona de nanofósseis da Petrobras N-560; modificado de Castro 1999).

da Bacia de Campos registram um importante evento isotópico caracterizado pelo substancial aumento relativo dos valores de $\delta^{18} \mathrm{O}(+1 \% 0)$. Interpreta-se que esse aumento corresponda ao evento Oi-1 de Miller et al. (op. cit.), e datado em 35.8 Ma e que pode ser correlacionado com a formação das correntes profun- das da águas frias da Antártica (proto-Antarctic Bottom Water, Kennett \& Stott 1990).

As rochas do Oligoceno Inferior, acima do evento Oi-1 de Miller possuem valores isotópicos mais negativos, e que se tornam ainda mais negativos para o topo (Figura 17). Este fato pode 


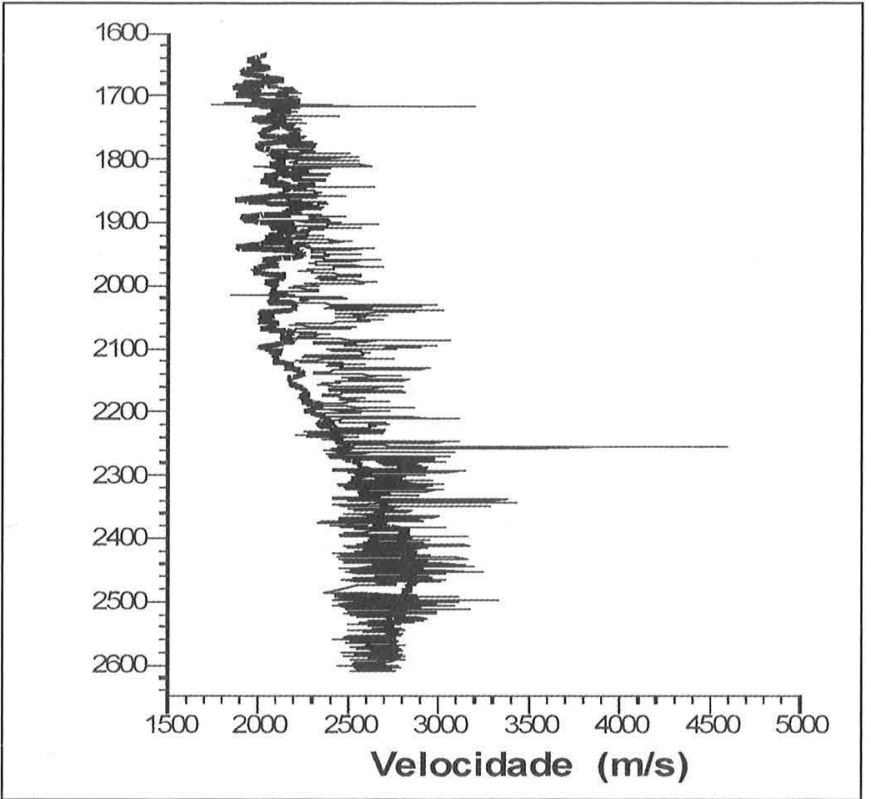

Figura 12 Comparação das freqüências encontradas no perfil sônico com as freqüências do traço de amplitude sísmica para as proximidades do poço. Na parte inferior do poço, a profundidades superiores a $2200 \mathrm{~m}$, ocorre uma diminuição substancial no conteúdo das altas freqüências. Interpreta-se esse fato a um aumento da velocidade intervalar devido ao incremento no teor de $\mathrm{CaCO}_{3}$, como conseqüencia de uma condensação da seção, ou seja, um decréscimo substancial na taxa de acumulação e um aumento relativo na concentração de carapaças de foraminiferos e nanofósseis (modificado de Castro 1999).

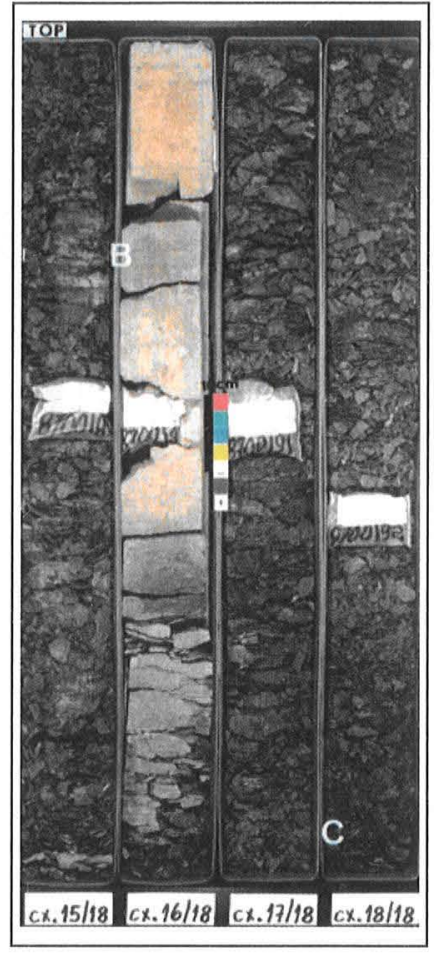

Figura 13 Folhelhos e margas de ambiente batial superior do Mioceno Inferior. Observe o aumento na espessura das camadas tanto de folhelho quanto nas de margas, comparativamente com os ciclos da seção do Oligoceno (Figura 9). Isto se deve ao aumento na taxa de acumulação principalmente relacionada com a sedimentação dos folhelhos.

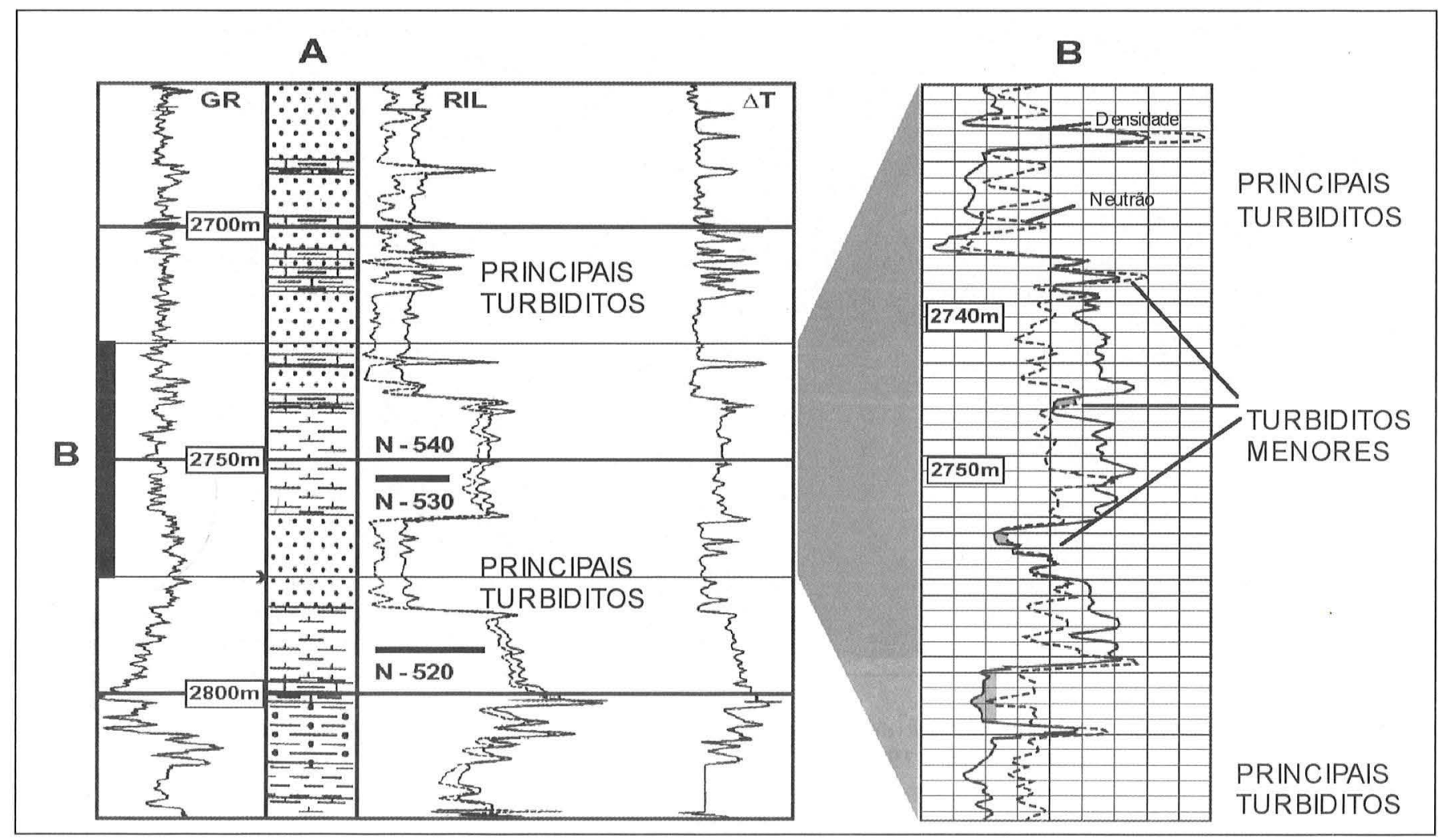

Figura 14 Padrão de perfil em forma de caixote, principalmente nos perfis de resistividade e sônico, representando o principal evento turbiditico do Oligoceno (b) Detalhe dos perfis de densidade-neutrão mostrando a existência de camadas menos espessas de arenitos turbiditicos dentro da seção de sedimentação hemipelágica representada por margas e folhelhos (modificado de Azambuja Filho 1990). 


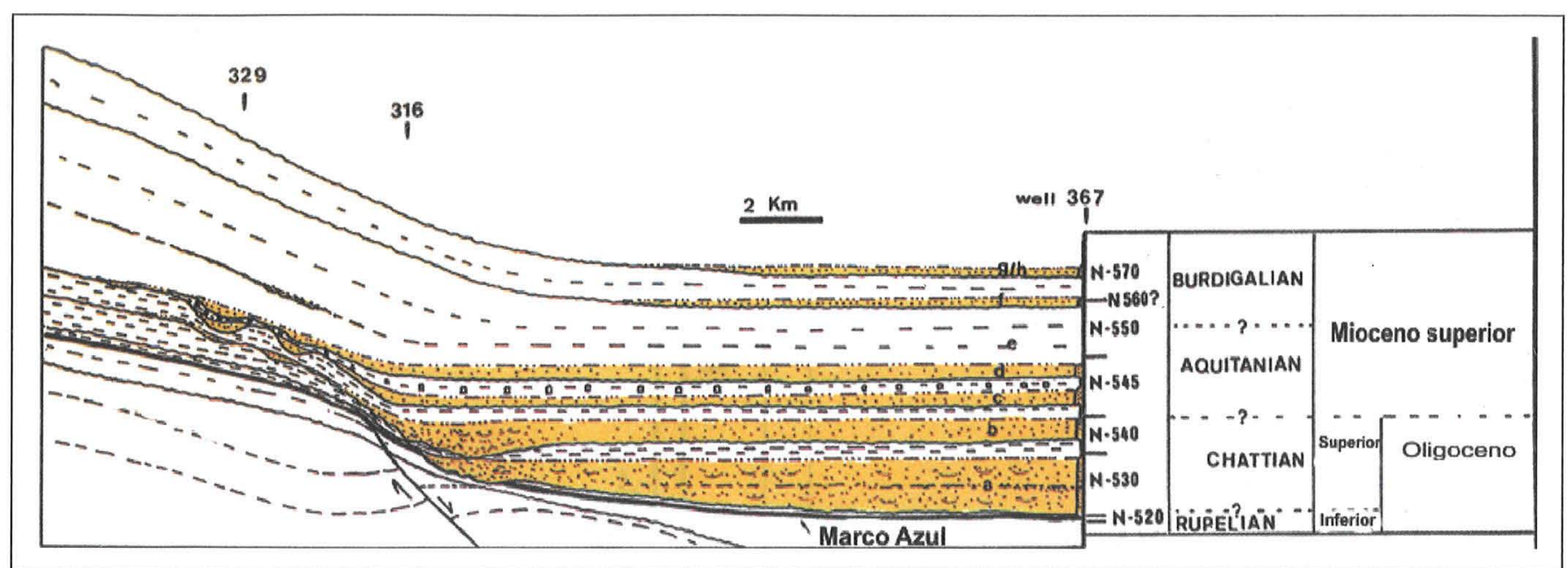

Figura 15 Representação esquemática dos principais sistemas turbidíticos do Oligoceno e do Mioceno inferior da Bacia de Campos (modificado de Azambuja Filho 1990).

ser interpretado como um aquecimento relativo da águas do mar entre 35 e $32 \mathrm{Ma}$, a semelhança do que foi proposto por Miller et al. (op. cit.). Na parte superior do Oligoceno Inferior ocorre um intervalo de intercalações de margas e carbonatos (chalk), denominado de "Marco Azul", com quantidades anômalas de uma espécie de nanofóssil identificada como Braarudosphaera sp por Gamboa et al. (1986). Importantes flutuações nos valores isotópicos de $\delta^{18} \mathrm{O}$ e $\delta 13 \mathrm{C}$, no teor de $\mathrm{CaCO}_{3}$ e no de carbono orgânico total (TOC) ocorrem associadas a este intervalo estratigráfico, e que segundo Shimabukuro (1994) representa um importante evento oceanográfico em resposta a ressurgência oceânica de águas frias enriquecidas de nutrientes e que aumentaram a produtividade primária local (Azevedo et al., 1994).

Adicionalmente, dois outros marcos isotópicos reconhecidos por Miller et al. (1991) nos poços do DSDP também foram identificados nesta seção da Bacia de Campos. São os eventos Oi-2 e Oi-2a caracterizados por fases de enriquecimento em $\delta^{18} \mathrm{O}$ nos carbonatos oceânicos e datados entre 32-30,5 Ma e em torno de $28 \mathrm{Ma}$, respectivamente (Figura 17). Durante o intervalo de tempo entre este dois eventos os valores isotópicos do oxigênio se mantiveram menos negativos, indicando a expansão das calotas polares. Já os valores isotópicos da seção de idade Oligoceno superior para cima mostram valores mais baixos de $\delta^{18} \mathrm{O}$, tanto em Campos quanto na curva global de Miller et al. (1991). Esta tendência é modificada na passagem do Oligoceno para o Mioceno, quando um outro episódio, de aumento significativo nos valores de $\delta^{18} \mathrm{O}$ dos carbonatos é registrado, indicando um outro episódio de resfriamento das águas oceânicas.

A importância da identificação e correlação estratigráfica destes eventos paleoceanográficos de escala global são de grande importância para o refinamento geocronológico das seções sedimentares brasileiras. Uma vez obtida a calibração geocronológica destes eventos em escala global, a calibração dos ciclos sedimentares de mais alta freqüência como os de precessão, obliqüidade e excentricidade podem ser melhor avaliados, permitindo um refinamento geocronológico de altíssima resolução.

Ciclo de $\mathrm{CaCO}_{3} \%$ versus assinatura isotópica $\mathrm{Na}$ seção sedimentar testemunhada no poço A (Oligoceno superior: + 26,5 a 23,9 Ma) identifica-se uma tendência geral de decréscimo na percentagem de carbonato de cálcio enquanto que os valores de $\delta^{18} \mathrm{O}$ aumentam (Figura 18a). Pode-se interpretar que esse aumento nos valores de $\delta^{18} \mathrm{O}$ esteja representando a uma tendência de resfriamento das águas oceânica na terceira ordem. Asso- ciado em conjugação de eventos, observa-se também que ocorre um aumento no influxo de material siliciclástico na região estudada, o que estaria indicando uma reorganização nas áreas fontes da bacia, provavelmente como resultado de um incremento na umidade das bacias de drenagem. Na porção superior desta seção testemunhada ocorrem valores elevados de $\mathrm{CaCO}_{3} \%$ correspondendo a baixos valores de $\delta^{18} \mathrm{O}$ (Figura 18b). Essa relação entre o teor de carbonato e os valores isotópicos de oxigênio são similares à relação observada no registro do Quaternário, onde os altos valores de $\mathrm{CaCO}_{3} \%$ correspondem a períodos interglaciais e que por conseqüência possuem valores baixos de $\delta^{18} \mathrm{O}$ (Be et al. 1976). Contudo, na base da seção testemunhada, ocorrem valores que apresentam uma correspondência direta entre o aumento do teor de carbonato de cálcio e o aumento nos valores do $\delta^{18} \mathrm{O}$ (Figura 18c). Esta situação poderia ser explicada como resultado de uma alta produtividade carbonática, como resultado de ressurgência de águas frias e ricas em nutrientes, como sugerido para o intervalo do "Marco Azul", e como conseqüência da baixa temperatura ocorreria um aumento nos valores de $\delta^{18} \mathrm{O}$, explicando assim a diferença para o modelo do Quaternário.

Como conclusão, as relações encontradas entre a variação nos valores de $\mathrm{CaCO}_{3} \%$ e de $\delta^{18} \mathrm{O}$ podem ser explicados como resultado de produtividade carbonática versus diluição de siliciclásticos refletindo um fenômeno regional, o qual não tenha necessariamente afetado a assinatura isotópica global. Um outro aspecto interessante consiste na relação entre o $\mathrm{CaCO}_{3} \%$ e os valores de $\delta^{18} \mathrm{O}$ obtidos por meio de análises espectrais (Figura 16b). Os periodogramas obtidos mostram que existe uma relação entre as oscilações dos valores de $\delta^{18} \mathrm{O}$ na escala de periodicidades orbitais, mas suas significâncias são bem menos importantes quando comparadas com as observadas na fábrica carbonática representada pelas variações nos valores de $\mathrm{CaCO}_{3} \%$ (Figura 16a).

Conclusões sobre a aplicação estratigráfica de isótopos estáveis A seção sedimentar do Oligoceno ao Mioceno da Bacia de Campos registrou em sua fábrica carbonática de água profunda, representada basicamente pelo acúmulo de carapaças de foraminíferos e nanofósseis, a indução periódica dos ciclos de precessão, obliqüidade e excentricidade curta e longa. Quanto às assinaturas isotópicas, derivadas de amostras de rocha total de amostras de testemunhos e calha, também registraram eventos importantes, os quais foram comparados com eventos 

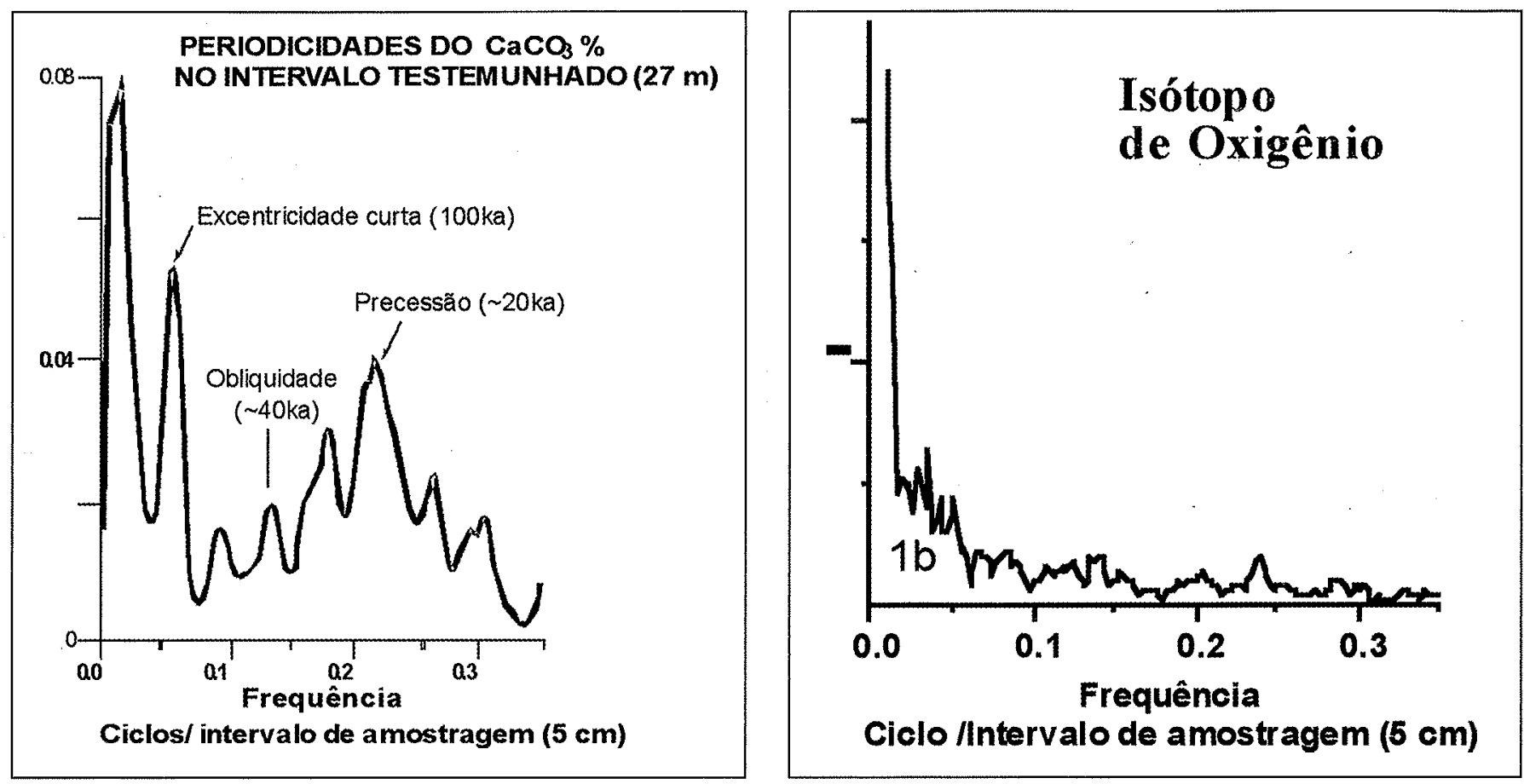

Figura 16 - Periodogramas, mostrando o domínio das freqüiencias correlacionadas à precessão, excentricidade curta e longa, com subordinação das freqüências correlacionáveis à obliqüidade para o intervalo como um todo.

oceanográficos como o Oi1, Oi2 e Oi2a e suas ligações com as glaciações na Antártica.

Estes resultados confirmam que, mudanças geoquímicas globais ocorridas no ambiente marinho podem fornecer um meio confiável de execução de correlações cronoestratigráficas entre dados oceânicos e bacias marinhas marginais; o que certamente irá contribuir para uma maior acurácia nas avaliações dos eventos biológicos, sedimentológicos e tectônicos.

A existência de intervalos estratigráficos cujos valores de $\delta^{18} \mathrm{O}$ e de $\mathrm{CaCO}_{3} \%$ estão em fase ou fora de fase, ou seja possuem uma relação direta ou inversa, reflete a importância de eventos regionais na relação da produtividade versus diluição por siliciclásticos em águas profundas e sua relação com as oscilações dos valores de $\delta^{18} \mathrm{O}$ no registro global. Como a variação no grau de insolação tem um forte controle orbital e como conseqüência as variações do volume de gelo nas calotas polares controlam a intensidade das correntes oceânicas e suas temperaturas é de se assumir que as variações observadas na relação de $\delta^{18} \mathrm{O}$ e de $\mathrm{CaCO}_{3} \%$ possam estar refletindo as mudanças entre períodos climáticos dominados pela precessão e pela obliqüidade em suas modulações relativas às excentricidades curta e longa. Contudo, em intervalos do Mioceno Médio a Superior os ciclos associados à obliqüidade passam a ser os dominantes.

Conforme discutido anteriormente, e também exemplificado por Imbrie et al. (1984), essas mudanças nos isótopos em carapaças de foraminíferos e sua relação com os ciclos de Milankovitch alteram-se para determinados períodos de tempo geológico. Isto pode ser explicado pela alternância no domínio das modulações, quando a excentricidade se aproxima de zero, a insolação deixaria de ser dominada pela precessão e passaria para o domínio da obliqüidade, o que poderia explicar as relações discutidas acima em relação aos ciclos carbonáticos.

Sob o ponto de vista metodológico, fica demonstrado que é possível utilizar amostras de rocha total oriundas de amostras de calha em estudos estratigráficos isotópicos, assim garantindo a uso de isótopos estáveis como uma ferramenta de rotina na pesquisa estratigráfica.

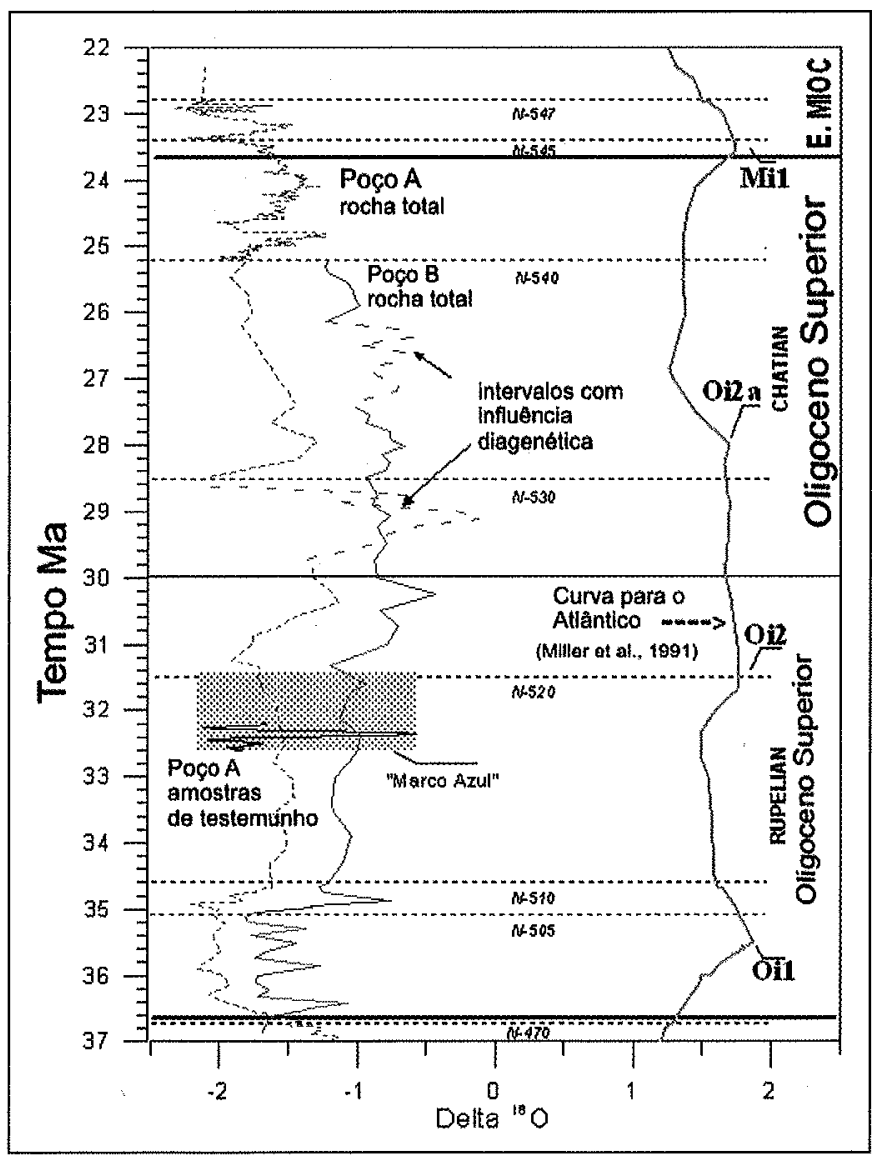

Figura 17 - Curvas isotópicas de oxigênio para o Atlântico (modificado de Miller et al., 1991) e de dois poços da bacia de Campos (modificado de Azevedo et al., 1994). A escala temporal utilizada para definir os limites bioestratigráficos foi a de Berggren et al., (1985) e as biozonas foram definidas por Richter et al. (1993). 


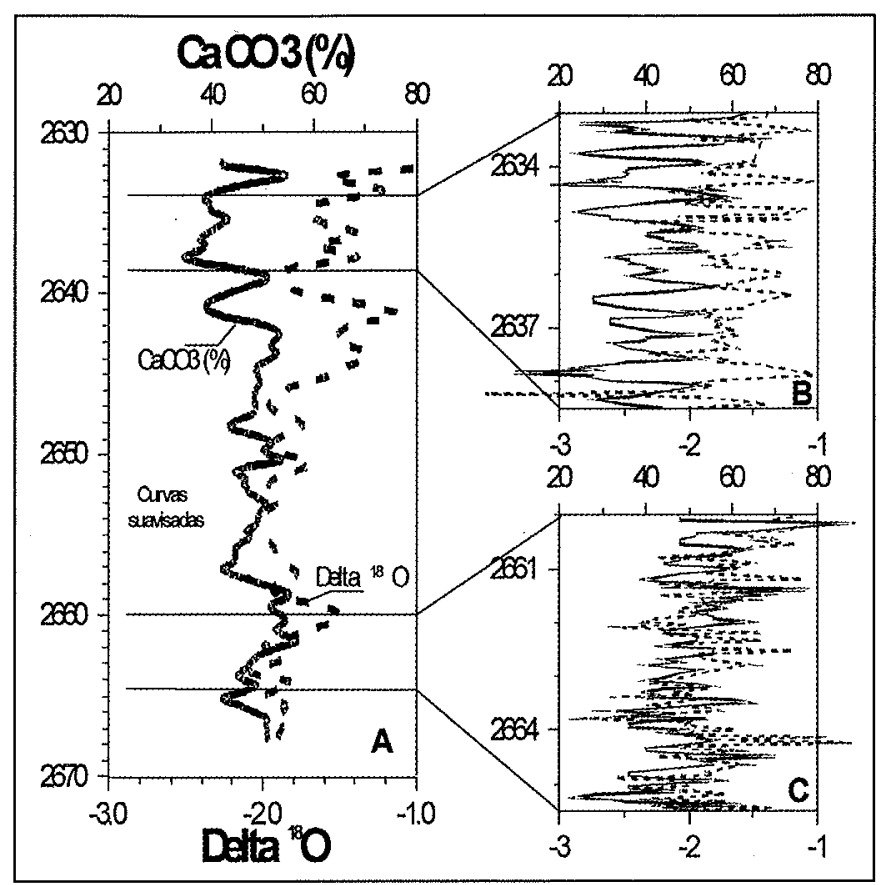

Figura 18 - Variação dos valores de $\mathrm{CaCO}_{3} \%$ e de ${ }^{18} \mathrm{O}$ com a profundidade, mostrando as tendências ciclicas na ordem de excentricidade longa das relações entre estas duas variáveis e um aumento geral nos valores de ${ }^{18} \mathrm{O}$ indicando um resfriamento para o parte superior na seção de idade oligocênica na bacia de Campos (modificado de Azambuja Filho \& Azevedo, 1995). Observe nas duas seções da figura A amplificadas nas figuras $B$ e $\mathrm{C}$ que existe uma mudança na relação entre o de $\mathrm{CaCO}_{3} \%$ e de _ ${ }^{18} \mathrm{O}$, na figura $B$ os valores apresentam relação inversa e na $C$ uma relação direta.
SUMÁRIO E DISCUSSÕES Ciclos de variação do nível do mar causados por mudanças nas massas de gelo glaciais nos pólos, tendem a seguir os ciclos de insolação: o nível do mar fica alto quando a insolação é máxima e baixo quando a insolação é mínima. Adicionalmente, a sucessão climática de cada banda relativa do ciclo de insolação é diferente, causando variações no relacionamento das fases de produção de sedimento em relação ao nível do mar. A inclusão do impacto do clima nas interpretações estratigráficas poderá permitir previsões mais acuradas na ocorrência dos principais elementos do sistema petrolífero de uma determinada bacia.

A cicloestratigrafia, como refinamento estratigráfico e geocronológico, foi realizada na seção do Oligoceno-Mioceno da Bacia de Campos com sucesso e permitiu compreender a presença de dois tipos de padrões estratigráficos, um caracterizado por depósitos espessos (dezenas de metros) de arenitos, e outro com intervalos mais freqüentes e mais delgados (alguns metros) imersos em depósitos hemipelágicos. A análise cicloestratigráfica determinou que os arenitos delgados recorreriam a intervalos de aproximadamente 400 a $500 \mathrm{ka}$, o que equivaleria a ciclos de excentricidade longa. Já os eventos com arenitos de maior espessura, apresentam uma recorrência que varia de 1,2 a $1,5 \mathrm{Ma}$, provavelmente resultante da superposição de efeitos de alta periodicidade e eventualmente ampliados por algum evento tectônico.

A combinação da cicloestratigrafia e da quimioestratigrafia mostrou que existe ainda um grande potencial de pesquisa a ser explorado e compreendido nos registros sedimentares antigos.

Agradecimentos Agradecemos a Petrobras a Chevron Energy. pela permissão de publicar esta trabalho. Gostaríamos de agradecer Sidnei Rostirrola da Universidade Federal do Paraná, pela revisão desta versão em português e ao Heriberto V. dos Santos pela confecção dos desenhos.

\section{Referências}

Azambuja Filho N.C. de 1990. The Oligo-Miocene turbidites and associated facies of Campos basin, offshore Brazil. Tese de Doutorado, Imperial College of London, Londres, $456 \mathrm{p}$.

Azambuja Filho N.C. de \& Azevedo R.L.M. de 1995. Cyclostratigraphy and stable isotopes in the Oligocene-Miocene succession of the Campos basin. In: 1st Workshop of Paleoceanography with Emphasis on Micropaleontology and Stratigraphy, Gramado, Brazil, p. 27-33.

Azevedo R.M.L., Rodrigues R., Takaki T. 1994. Isotopic stratigraphy and paleoceanographic aspects of the Oligocene-lower Miocene of Campos Basin, Southeast of Brasil. In: Internacional Sedimentological Congress, 14. Recife, 1994. Abstracts . Recife: Abstacts, p. G-9.

Be A.W.H., Damuth J., Lott L., Free R. 1976. Late climatic record in the western equatorial Atlantic sediment. In: Clime R.M. \& Hays J.D. (eds.). Investigations of late Quaternary Paleoceanography and paleoclimatology. Boulder: The Gological Society of America, Memoir, 145:165-200.

Berggren W.A., Kent D.V., Flynn J.J., Van Couvering J.J. 1985. Cenozoic geochronologic. Geol. Soc. Am. Bull., 96:1407-1418.

Castro A.H.A. de 1999. Estudo de ciclicidade orbital com base em dados sísmicos exemplo para a bacia de campos, Brasil. Dissertação de Mestrado, Instituto de Geociências, UFRGS, $147 \mathrm{p}$.

Chatfield C. 1989. The Analysis of Time Series - An Introduction.
Chapman and Hall. London, $241 \mathrm{pp}$.

Davis J.C. 1986. Statistics and Data Analysis in Geology. John Wiley $\&$ Sons, Singapore $646 \mathrm{pp}$.

Einsele G., Ricken W. and Seilacher A. 1991. Cycles and events in stratigraphy, basic concepts and terms. In: Einsele G., Ricken W., Seilacher A. (eds.), Cycles and Events in Stratigraphy, SpringerVerlag, Berlin, pp.: 1-19.

Gamboa L.A.P., Esteves F.P., Shimabukuro S., Carminatti M., Peres W.E., Cruz C.E.S. 1986. Evidências de variações de nível de mar durante o Oligoceno e suas implicações faciológicas. In: Congresso Brasileiro de Geologia, 34. Goiânia. Anais S.B.G. 1:8-22.

Haq B.U., Hardenbol J., Vail P.R. 1987. Chronology of fluctuating sea levels since the Triassic, Science, 235: 1156-1167.

Imbrie J. and Imbrie K.P. 1979. Ice Ages - Solving the Mystery. Cambridge, Harvard University Press, 224 pp.

Imbrie J., Hays J.D., Martinson D., Mcintyre A., Mix A., Morley J., Pisia N., Prell W. \& Shackleton N.J. 1984. The orbital theory of Pleistocene climate: Support from a revised chronology of marine delta $\mathrm{O}^{18}$ record. In: Berger A.L. et al. (eds) Milankovitch and climate, Part 1, D. Reidel, London, pp.: 269-305.

Kennett J.P. \& Stott L.D. 1990. Proteus and proto-oceanus: ancestral Paleogene oceans as revealed from Antartic stable isotopic results; 
ODP Leg 113. In: Barker P.F. et al. (eds.), Proceedings of the Oceanic Drilling Program. Scientific Results, 113. College Station. Oceanic Drilling Program. Pp.: 865-880.

Kukal Z. 1990. The rate of sedimentation. In: Kukal Z. (ed.), 1990. The Rate of Geological Processes, Earth-Science Reviews Special Issue, 28, n.1, 2, 3, Amsterdam, pp.: 94-133.

Matthews R.K., Frohlich C. 1991. Orbital forcing of low frequency glacioeustasy, Journal of Geophysics Research, 96 B4: 6797-6803.

Milankovitch M. 1941. Kanon der Erdbestranlung and seine anwendung auf das eiszeitenproblem (Canon of insolation and the ice age problem): Transactions of the Royal Serbian Academy, Belgrade, Spec. Pub. v. 132, Section of Mathematical and Natural Sciences, 33: 674 p. (English translation by the Israeli program for scientific translation. Published by the U.S. Dept. of Commerce and the National Science Foundation, Wash. D.C., NTIS Rept. SFCSICOMM (TT-67-514010-1-2), 1969, 507 pp.

Miller K.G., Wright J.D., Fairbanks R.G. 1991. Unlocking the ice house: Oligocene-Miocene isotopes, eustasy, and margin erosion. Jour: Geoph. Research, 96: 6829-6848.

Perlmutter M.A. and Matthews M.D. 1989. Global cyclostratigraphy: A Model. In: Cross, T. (ed.), Ouantitative Dynamic Stratigraphy, Prentice Hall, N.J., pp.: 233-260.

Perlmutter M.A, \& Plotnick R.E. 1997. Hemispheric asymmetry of the marine stratigraphic record; proof of the existence of a polar icecap. In: A.A.P.G. Annual Meeting Abstracts with Programs, Dallas Tx, p. A92.

Perlmutter M.A. \& Plotnick R.E. 2002. Predictable variations in the marine stratigraphic record of the northern and southern hemispheres and reservoir potential. In: Armentrout J.M. and Rosen N.C (eds.), Sequence Stratigraphic Models for Exploration and Production: Evolving Methodology, Emerging Models and Application Histories, 22nd Ann. Gulf Coast Section Soc. for Sed. Geol. (SEPM). Proceeding, pp.: 231-256.

Perlmutter M.A., Plotnick R.E. 2003. Hemispheric asymmetry of the marine stratigraphic record; conceptual proof of a unipolar icecap, in Cecil C.B. and Edgar N.T. (eds.), Climate Controls on Stratigraphy, Soc. for Sed. Geol. (SEPM) Spec. Pub 77. pp.: 5166.

Perlmutter M.A. and Azambuja Filho N.C. de 2005. Cyclostratigraphy, In: Koutsoukos, E.A. (ed.). Applied Stratigraphy, Topics in Geobiology, volume 23, Springer, pp.: 301-338.

Plotnick, R, Gardner, R, O'Neill, R, 1993, Lacunarity indices as measures of landscape texture, Landscape Ecology, 8: 201-211.

Plotnick R.E., Gardner R.H., Hargrove W.H., Prestegaard K., Perlmutter M.A. 1996. Lacunarity analysis: a general technique for the analysis of spatial patterns, Phys. Rev. E. pp. 1-8.

Richter A.J., Gomide J., Shimabukuro S., Antunes R.L. 1993. Bioestratigrafia dos nanofósseis cenozóicos da margem continental brasileira. Relatório Interno, PETTROBRÁS/CENPES, Rio de Janeiro, $45 \mathrm{p}$.

Sadler P.M. \& Strauss D.J. 1990. Estimation of completeness of stratigraphic sections using empirical data and theoretical models. Jour. Geol. Soc. London, 147:471-485.

Schwarzacher W. 1975. Sedimentation models and quantitative stratigraphy. In: Developments in Sedimentology 19. Elsevier Pub., Amsterdam, $382 \mathrm{p}$.

Schwarzacher W. 1993. Cyclostratigraphy and the Milankovitch Theory. In: Developments in Sedimentology 52, Elsevier, Amsterdam, $225 \mathrm{p}$.

Shimabukuro S. 1994. "Braarudosphaera Chalk": Investigações sobre a gênese de um marco estratigráfico. Dissertação de Mestrado, Instituto de Geociências, UFRGS, Porto Alegre, $127 \mathrm{p}$.

Vail P.R., Mitchum R.M., Thompson S. III 1977. Seismic stratigraphy and global changes of sea level, Part 3: Relative changes in sea level from coastal onlap. In: Payton C.E. (ed.), Seismic stratigraphy -Applications to Hydrocarbon Exploration, Amer. Assoc. of Petrol. Geol. Mem. 26, pp. 63-82. 